\title{
Incremental Shuttle Walk Test to Assess and Prescribe Exercise for Subjects With Bronchiectasis: Hallway Versus Treadmill
}

\author{
Cristiane S Oliveira PT, Anderson José PT PhD, Crislaine O Santos, \\ Cristiane H Y de Oliveira PT MSc, Thiago C O Carvalho, Rejane A S de Castro PT MSc, \\ Jessyca P R Selman PT MSc, Anderson A de Camargo PT PhD, and Simone Dal Corso PT PhD
}

\begin{abstract}
INTRODUCTION: The incremental shuttle walk test was initially developed to be carried out in a hallway (ISWT-H) but has been modified to be performed on a treadmill (ISWT-T). However, it is still unknown whether performance on ISWT-H and ISWT-T are similar in patients with bronchiectasis. In this study, we compared the performance, physiological responses, and perception of effort between the ISWT-T with a handrail and ISWT-H for subjects with bronchiectasis. We also sought to estimate and compare the prescription for training intensity with both tests. METHODS: This was a cross-sectional study in which 24 subjects with bronchiectasis were evaluated on 2 different days ( $24 \mathrm{~h}$ apart). Distance walked (m) was compared between the ISWT-H and ISWT-T. A training session was held on a treadmill at $75 \%$ of the speed obtained from both tests. The walking distance, oxygen uptake $\left(\dot{\mathrm{V}}_{\mathrm{O}_{2}}\right)$, carbon dioxide production $\left(\dot{\mathrm{V}}_{\mathrm{CO}_{2}}\right)$, heart rate, and ventilation $\left(\dot{\mathrm{V}}_{\mathrm{E}}\right)$ were measured. RESULTS: There was a difference in the walking distance between the ISWT-T and ISWT-H, but physiological responses for $\dot{\mathrm{V}}_{\mathrm{O}_{2}}, \dot{\mathrm{V}}_{\mathrm{CO}_{2}}$, heart rate, and $\dot{\mathrm{V}}_{\mathbf{E}}$ were similar. However, the speed estimated for training was different, as were the $\dot{\mathrm{V}}_{\mathrm{O}_{2}}, \dot{\mathrm{V}}_{\mathrm{CO}_{2}}$, and heart rate. CONCLUSIONS: The ISWT-T with handrail and the ISWT-H are not interchangeable in subjects with bronchiectasis. A slower speed of training intensity may occur when the test is performed in a hallway, as originally described, and this may underestimate responses to aerobic training. Key words: bronchiectasis; exercise; walking; exercise tolerance. [Respir Care 2018;63(3):311-318. ( ) 2018 Daedalus Enterprises]
\end{abstract}

\section{Introduction}

The incremental shuttle walking test (ISWT) allows the determination of cardiopulmonary responses that are equivalent to those found with the maximum cardiopulmonary test. ${ }^{1}$ Thus, the ISWT is used for the evaluation and prescription of exercise intensity in a pulmonary rehabilitation program. ${ }^{2,3}$ The walking-based test was initially developed to be carried out in a hallway (ISWT-H), but it has

\footnotetext{
All of the authors are affiliated with the postgraduate program in Rehabilitation Sciences, Universidade Nove de Julho, São Paulo/SP, Brazil.

The authors disclose no conflicts of interest.

Correspondence: Anderson José PT PhD, Postgraduate Program in Rehabilitation Sciences, Nove de Julho University, Rua Vergueiro, 235/249, Liberdade, São Paulo SP 01504-001. E-mail: dr.andersonjose@gmail.com.
}

DOI: $10.4187 /$ respcare.05735 been modified to be performed on a treadmill (ISWTT). ${ }^{4-8}$ This modification occurred because of the lack of available and appropriate physical space, which is a common disadvantage with this test. In additional, continuous monitoring and oxygen supplementation makes performing these tests difficult.

Compared to the ISWT-H, a substantial reduction in the walking distance has been demonstrated for the 6-min walk test, ${ }^{4,5}$ the 12 -min walk test, ${ }^{6,7}$ and the ISWT ${ }^{8}$ when performed on a treadmill, along with a higher energy cost per meter on the ISWT. ${ }^{9}$

Indeed, there are important differences in gait mechanics between walking on a treadmill and walking in a hallway. ${ }^{5,9-11} \mathrm{~A}$ treadmill requires greater effort and energy to maintain lateral balance and is an activity with which many patients are not familiar. ${ }^{11-13}$ Therefore, because the 2 methods of performing these tests are not interchangeable, the replacement of the hallway with a treadmill is not recommended. ${ }^{14}$ 
There is, however, a considerable reduction in demands when a patient walks on a treadmill with a handrail. This strategy reduces the effort required to maintain balance, reducing energy expenditure, ${ }^{11-13}$ as well as reducing oxygen uptake, ${ }^{15-17}$ step variability, ${ }^{11,18}$ heart rate, perception of effort, ${ }^{16,17}$ and increased exercise time. ${ }^{19}$ The training velocity on a treadmill based on the results of an ISWT performed in a hallway does not consider the effects of handrail support during physical training. Additionally, pulmonary rehabilitation guidelines do not comment on this resource. ${ }^{20}$

It is still unknown whether performance on an ISWT conducted on a treadmill with a handrail is similar to that performed in a hallway, or whether this modality would influence the intensity of training. Thus, we aimed to compare the performance, physiological responses, and perception of effort during the ISWT performed in a hallway to those from an ISWT performed on a treadmill with a handrail in subjects with bronchiectasis. A further aim was to evaluate submaximal responses during a treadmill training session based on the speed determined by the 2 forms of the ISWT (hallway and treadmill).

\section{Methods}

\section{Study Design}

A cross-sectional study was performed on 2 consecutive days.

\section{Recruitment and Selection of Subjects}

Researchers recruited a convenience sample from the Obstructive Disease Out-Patient Clinic at the Hospital das Clínicas da Universidade de São Paulo. Participants were sent to the University Center for tertiary cardiopulmonary rehabilitation (Universidade Nove de Julho) from May 2015 until May 2016. After written and verbal explanations regarding the objectives and procedures of the study, all participants signed a consent form before starting the assessments. This study received approval from the Human Research Ethics Committee of Universidade Nove de Julho, São Paulo/SP, Brasil (n. 451538) and the University of São Paulo (0921/11).

\section{Inclusion and Exclusion Criteria}

Bronchiectasis was diagnosed by the medical staff of the Obstructive Disease Out-Patient Clinic at the Hospital das Clínicas da Universidade de São Paulo based on clinical and tomographic evaluations according to the criteria of the International Guidelines for this disease. ${ }^{21}$

In a convenience sample, 24 subjects (15 male) with bronchiectasis with a sedentary lifestyle (physical activ-

\section{QUICK LOOK}

\section{Current knowledge}

The incremental shuttle walk test (ISWT) can be used for both the evaluation and prescription of exercise intensity in a pulmonary rehabilitation program. This test was initially developed to be carried out in a hallway, but it has been modified to be performed on a treadmill when there is inadequate space to perform the test. However, the 2 modalities of the test are not interchangeable because there are differences between the mechanics of walking on a treadmill compared to those of walking in a hallway, with a greater energy expenditure on the treadmill, which can be diminished by the handrail support.

\section{What this paper contributes to our knowledge}

In subjects with bronchiectasis, the ISWT on a treadmill with handrail support should not be considered as an alternative to the ISWT in the hallway. The handrail support reduces the energy expenditure and overestimates the distance traveled. Therefore, the test should be used in its original form. Independent of how the physical training load is determined (on a treadmill or in a hallway), the subjects' responses during training were compatible with moderate intensity.

ity $<150$ min per week) and no changes in medication, sputum color, or shortness of breath in the preceding 4 weeks were consecutively included. Individuals with a history of smoking, neuromuscular or musculoskeletal disease, cardiopulmonary disease, acute infectious disease, a need for oxygen during the tests or training sessions, and those who did not complete the evaluations were excluded. No subject participated in physical training before being enrolled in the study.

\section{Procedures}

On the first day, spirometry was performed and body mass index was calculated. The participants were classified as underweight $\left(<18.5 \mathrm{~kg} / \mathrm{m}^{2}\right)$, ideal weight $\left(18.5-24.9 \mathrm{~kg} / \mathrm{m}^{2}\right)$, overweight $\left(25-29.9 \mathrm{~kg} / \mathrm{m}^{2}\right)$, or obese $\left(\geq 30.0 \mathrm{~kg} / \mathrm{m}^{2}\right) .{ }^{22}$ The subjects were randomized to perform either the treadmill test (ISWT-T) or the hallway test (ISWT-H) first and then to take the other test the next day. Thirty minutes after each test, a 20-min training session was held at $75 \%$ of the maximum speed obtained during the ISWT-T or the ISWT-H. No subject had previous contact with the ISWT. 


\section{Assessments}

Spirometry. Spirometry was performed using the ULTIMA CPX (Medical Graphics, St. Paul, Minnesota) according to the technical procedures recommended by the Brazilian Pneumology Society. ${ }^{23}$ The values were compared to those predicted for the Brazilian population. ${ }^{24}$ Dyspnea levels were evaluated with the modified Medical Research Council scale. ${ }^{25}$

ISWT-H. The ISWT-H was performed according to the original description $^{1}$ in a hallway $10 \mathrm{~m}$ long. This distance was marked by 2 cones that were placed $0.5 \mathrm{~m}$ from each edge. The individual followed this route at a predetermined speed imposed by an audible pre-recorded rhythm. The ISWT is composed of 12 levels, each lasting $1 \mathrm{~min}$, with an initial speed of $0.5 \mathrm{~m} / \mathrm{s}$ and increments of $0.17 \mathrm{~m} / \mathrm{s}$ each minute, reaching a maximum speed of $2.37 \mathrm{~m} / \mathrm{s}$. A single beep indicates that the individual should maintain the current speed, while a triple beep signifies the beginning of a new level of the test where the individual needs to walk faster. Running is not allowed. The test concludes when the individual cannot successfully reach one of the cones at the appropriate time of the sound stimulus $(0.5 \mathrm{~m}$ before the cone) twice. The physiotherapist may also stop the test if the subject experiences chest pain, intolerable dyspnea, leg cramps, staggering, diaphoresis, or a pale or ashen appearance. ${ }^{14}$

Heart rate (Polar Precision Performance; Polar Electro, Kem-skin, Finland) and oxygen saturation (9500; Nonin, Plymouth, Minnesota) were continuously measured during the test. Blood pressure and the Borg scale score for dyspnea and lower limb fatigue ${ }^{26}$ were obtained at rest and immediately after the end of the test. The walking distance was expressed in absolute values and as a percentage of the predicted value. ${ }^{27}$

ISWT-T. The ISWT-T was performed on a treadmill without tilting or incline (Millennium Classic, Inbrasport, Porto Alegre, RS, Brazil) following the same protocol used for the ISWT-H, but all participants were allowed to use the handrails for balance. The criterion for interruption of the ISWT-H was the subject being $0.5 \mathrm{~m}$ away from the cone at the time of the sound stimulus during 2 consecutive attempts. Then a demarcation line was marked with tape fixed to the bearing bar of the treadmill in parallel with the lower limb on each side of the treadmill to allow for a similar parameter of test interruption. Therefore, the ISWT-T was interrupted when subjects were $0.5 \mathrm{~m}$ away from the demarcation line 2 consecutive times. The same variables described for the ISWT-H were measured during the ISWT-T.
Aerobic Training Session. After each incremental test, subjects were given $30 \mathrm{~min}$ to rest before completing a training session. The treadmill session consisted of $5 \mathrm{~min}$ of warm-up, $15 \mathrm{~min}$ at the target velocity, and 5 minutes of cool-down. The training intensity was $75 \%$ of the maximum speed achieved on the ISWT-H or the ISWT-T, and a warm-up period was performed at $50 \%$ of the target speed. The handrail was used for balance by all subjects. The variables measured during the training session were the same as those described for the ISWT-H and ISWT-T.

Gas Exchange Analysis. During the 2 tests and the training session, a portable metabolic system (VO2000, Medical Graphics, St. Paul, Minnesota) was used to measure oxygen uptake $\left(\dot{\mathrm{V}}_{\mathrm{O}_{2}}\right)$, carbon dioxide production $\left(\dot{\mathrm{V}}_{\mathrm{CO}_{2}}\right)$, and ventilation $\left(\dot{\mathrm{V}}_{\mathrm{E}}\right)$. Before every test, the system was calibrated according to the manufacturer recommendations. Measurements were performed at rest in the sitting position and throughout the entire test. For the metabolic and ventilatory analyses, the peak of the average of the last 30 seconds of the tests and also the peak of the average of the last $3 \mathrm{~min}$ of the training sessions were considered.

\section{Statistical Analysis}

Data analysis was performed using the Statistical Package for the Social Sciences, version 20.0 (SPSS, Chicago, Illinois, United States). The Shapiro-Wilk test was used to determine the normality of the data. Parametric variables were expressed as mean (SD). Nonparametric variables were expressed as the median and interquartile range. A comparison of the groups at the peak of the tests and training sessions was performed using the Student paired $t$ test (parametric variables) or the Wilcoxon test (nonparametric variables) and Bland-Altman analysis. Comparisons between groups at each minute for $\dot{\mathrm{V}}_{\mathrm{O}_{2}}, \dot{\mathrm{V}}_{\mathrm{E}}$, and heart rate during the tests and $\dot{\mathrm{V}}_{\mathrm{O}_{2}}$ during the training sessions were performed using analysis of variance, generalized linear models, and the Bonferroni post hoc analysis. The effect size and sample power (a posteriori) was calculated using the $G *$ Power software program (Universität Dusseldorf, Germany). A $P$ value $<.05$ was considered indicative of statistical significance.

\section{Results}

Of 31 subjects with bronchiectasis recruited, 5 subjects were excluded for not completing the assessments. An additional 2 participants were excluded due to their need for oxygen during training. Thus, the final sample was composed of 24 subjects, of whom 15 were men. Using the ISWT as the outcome, the sample power was 0.84 . No adverse events occurred during testing or training. Base- 
line characteristics are shown in Table 1, and the spirometric analyses revealed, on average, an obstructive pattern.

A significant difference was found in the performance on the ISWT-T in comparison to the ISWT-H, with a greater walking distance and a more advanced stage

Table 1. Baseline Characteristics

\begin{tabular}{|c|c|}
\hline Subject Attributes & Mean $(\mathrm{SD})^{*}$ \\
\hline Age, y & $49(16)$ \\
\hline Male/female, $n$ & $15 / 9$ \\
\hline Weight, kg & $62.1(13.0)$ \\
\hline Height, m & $1.6(0.1)$ \\
\hline Body mass index, $\mathrm{kg} / \mathrm{m}^{2}$ & $24.0(4.7)$ \\
\hline Underweight, $n(\%)$ & $2(8.3)$ \\
\hline Normal, $n(\%)$ & $11(45.8)$ \\
\hline Overweight, $n(\%)$ & $9(37.5)$ \\
\hline Obese, $n(\%)$ & $2(8.3)$ \\
\hline FVC, L & $2.7(1.0)$ \\
\hline FVC, $\%$ of predicted & $74.6(21.2)$ \\
\hline $\mathrm{FEV}_{1}, \mathrm{~L}$ & $1.6(0.8)$ \\
\hline $\mathrm{FEV}_{1}, \%$ of predicted & $55.3(24.6)$ \\
\hline $\mathrm{FEV}_{1} / \mathrm{FVC}$ & $0.59(0.14)$ \\
\hline MMRC & $3(2-3)$ \\
\hline \multicolumn{2}{|c|}{$\begin{array}{l}N=24 \\
* \text { Data are presented as mean }(\mathrm{SD}) \text {, except male/female ratio and MMRC score, which is } \\
\text { presented as median (interquartile range). } \\
\text { MMRC = modified Medical Research Council }\end{array}$} \\
\hline
\end{tabular}

achieved on the treadmill. Metabolic, cardiac, and ventilatory responses and perception of effort at the peak of the tests were similar (Table 2). The Bland-Altman analysis demonstrate mean error and limits of agreement for distance: $200.7 \mathrm{~m}$ ( -47.4 to $448.8 \mathrm{~m})$, the percentage of the predicted distance: $24.2 \%(-0.2$ to $1.9 \mathrm{~km} / \mathrm{h})$, and faster velocity: $0.86 \mathrm{~km} / \mathrm{h}(1.9$ to $-0.2 \mathrm{~km} / \mathrm{h})$.

The performance at every stage during the ISWT-H and ISWT-T demonstrated a linear increase in $\dot{\mathrm{V}}_{\mathrm{O}_{2}}, \dot{\mathrm{V}}_{\mathrm{E}}$, and heart rate in both tests. The results showed significant differences between the 2 tests during the same stage. $\dot{\mathrm{V}}_{\mathrm{O}_{2}}$ and ventilation were greater in the ISWT-H from the sixth stage, and the heart rate was higher from the seventh stage (Fig. 1).

During the training sessions, significant differences between groups were found for the metabolic, ventilatory, and cardiopulmonary responses due to the greater load determined by the ISWT-T in comparison to the ISWT-H (Table 3). There was no significant difference between groups for $\dot{\mathrm{V}}_{\mathrm{O}_{2}}(\mathrm{~mL} / \mathrm{kg} / \mathrm{min})$ during the training session (Fig. 2).

\section{Discussion}

In this study, performance, physiological responses, and perception of effort were compared during the ISWT-H

Table 2. Comparison Between ISWT-T and ISWT-H at Peak of Exercise

\begin{tabular}{|c|c|c|c|c|}
\hline Subject Attributes & ISWT-T & ISTW-H & $P$ & Effect Size \\
\hline Distance, $\mathrm{m}$ & $639(205)$ & $438(115)$ & $<.001$ & 1.21 \\
\hline Distance, $\%$ of predicted & $77.0(27.2)$ & $53.2(17.2)$ & $<.001$ & 1.02 \\
\hline Speed, km/h & $7.0(1.0)$ & $6.0(1.0)$ & $<.001$ & 1.00 \\
\hline Stages & $10.0(2.0)$ & $8.0(1.2)$ & $<.001$ & 1.21 \\
\hline Heart rate, beats/min & $131(16)$ & $129(16)$ & .43 & 0.11 \\
\hline Heart rate, $\%$ of predicted & $77.1(11.0)$ & $76.0(10.0)$ & .40 & 0.10 \\
\hline $\mathrm{S}_{\mathrm{pO}_{2}}, \%$ & $89.1(6.2)$ & $88.0(6.0)$ & .007 & 0.18 \\
\hline Borg dyspnea & $4(2.3-5.0)$ & $4(2.0-5.0)$ & .26 & 0.08 \\
\hline Borg lower limb fatigue & $4(2.0-7.0)$ & $3.5(1.3-6.5)$ & .08 & 0.19 \\
\hline$\dot{\mathrm{V}}_{\mathrm{O}_{2}}, \mathrm{~L} / \mathrm{min}$ & $1.3(0.3)$ & $1.4(0.5)$ & .19 & 0.24 \\
\hline$\dot{\mathrm{V}}_{\mathrm{O}_{2}}, \mathrm{~mL} / \mathrm{kg} / \mathrm{min}$ & $21.0(5.0)$ & $22.0(10.0)$ & .48 & 0.13 \\
\hline$\dot{\mathrm{V}}_{\mathrm{O}_{2}}, \%$ of predicted & $75.1(24.4)$ & $75.4(25.0)$ & .95 & 0.01 \\
\hline$\dot{\mathrm{V}}_{\mathrm{CO}_{2}}, \mathrm{~L} / \mathrm{min}$ & $1.1(0.4)$ & $1.2(0.4)$ & .27 & 0.78 \\
\hline$\dot{\mathrm{V}}_{\mathrm{E}}, \mathrm{L} / \mathrm{min}$ & $28.0(8.6)$ & $29.0(9.0)$ & .61 & 0.11 \\
\hline$\dot{\mathrm{V}}_{\mathrm{E}} / \mathrm{MVV}$ & $0.5(0.1)$ & $0.5(0.2)$ & .63 & 0.00 \\
\hline Respiratory quotient & $1.0(0.1)$ & $1.0(0.3)$ & .09 & 1.22 \\
\hline \multicolumn{5}{|c|}{$\begin{array}{l}N=24 \\
\text { Values are expressed as mean (SD), except Borg scales, which are expressed as median (interquartile range). } \\
\text { ISWT = incremental shuttle walk test (-T, on a treadmill; }-\mathrm{H} \text {, in a hallway) } \\
\dot{\mathrm{V}}_{\mathrm{O}_{2}}=\text { oxygen uptake } \\
\dot{\mathrm{V}}_{\mathrm{CO}_{2}}=\text { carbon dioxide production } \\
\mathrm{V}_{\mathrm{E}^{\prime} / \mathrm{MVV}}=\text { minute ventilation/maximum voluntary ventilation }\end{array}$} \\
\hline
\end{tabular}



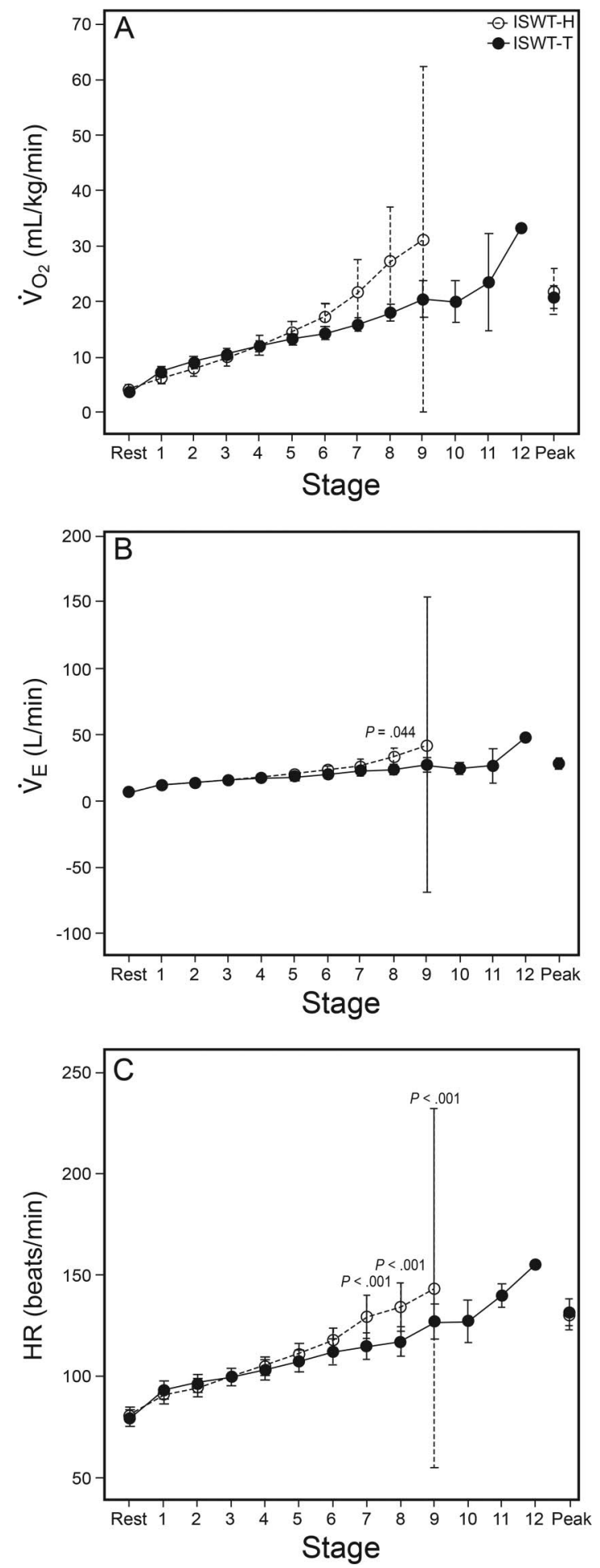

Fig. 1. Oxygen uptake $\left(\dot{\mathrm{V}}_{\mathrm{O}_{2}}, A\right)$, ventilation $\left(\dot{\mathrm{V}}_{\mathrm{E}}, \mathrm{B}\right)$, and heart rate (HR, C) per stage. Values are expressed as mean and $95 \% \mathrm{Cl} . \mathrm{N}=$ 24 until stage 5 . ISWT $=$ incremental shuttle walk test, $\mathrm{H}=$ hallway, and $\mathrm{T}=$ treadmill. and the ISWT-T with handrail support in subjects with bronchiectasis. Submaximal responses during a treadmill training session (also with handrail support) were evaluated for an isoworkload (at the same speed). The walking distance in the ISWT-T was greater, while the physiological responses were similar between tests. Due to the greater walking distance in the ISWT-T, the work load (speed) for physical training established by the test was a little higher and the physiological responses were clinically similar and compatible with a moderate intensity ${ }^{28}$ and below the recommendation for aerobic training. ${ }^{20,29}$

Unlike what has been demonstrated for the 6-min walk test, we hypothesized that the ISWT-T and ISWT-H could be interchangeable because the test is externally paced. In a previous study, subjects with cardiac disease demonstrated a poorer performance on a treadmill than in a hallway due to the greater energy expenditure required $(3.22 \pm 0.55 \mathrm{~J} / \mathrm{kg} / \mathrm{m}$ vs $3.00 \pm 0.41 \mathrm{~J} / \mathrm{kg} / \mathrm{m}) .{ }^{9}$ Our findings were different. A plausible explanation for this result is that all participants used the handrail for support, which demonstrates that this resource influences physiological responses, leading to better performance on the ISWT-T. Hence, the 2 methods of performing the test are not interchangeable.

Subjects were permitted to support themselves with the handrail because it is commonly used during treadmill training in a pulmonary rehabilitation program. Previous studies demonstrated that handrail use not only led to a greater walking distance in the ISWT-T but also affected the subjects' physiological responses, which may have been higher without this support. ${ }^{11,15,16,19}$ A possible explanation for this finding is that walking on a treadmill requires additional effort to maintain balance, and the use of a handrail for support compensates for this effort, reducing the demand required to maintain balance and consequently reducing the energy expenditure. ${ }^{11-13}$

The primary mechanisms for maintaining balance when walking are a variable step width ${ }^{18}$ and the arm swing. ${ }^{12,13}$ It has been demonstrated that there are no differences regarding the time interval and distance of the steps when walking in a hallway or on a treadmill. ${ }^{7,11}$ However, the balance provided by arm movements when walking is so important that its restriction directly affects the interval between steps and step variability. ${ }^{18}$ Moreover, when a handrail is used while walking on a treadmill, the following measurements are reduced: step variability by as much as $12 \%,{ }^{11,18}$ heart rate by 18 beats/min, energy expenditure by $2.81 \mathrm{kcal} / \mathrm{min}$, perception of effort using the Borg scale by 1.92 points, ${ }^{16}$ and $\dot{\mathrm{V}}_{\mathrm{O}_{2}}$ by $0.175 \mathrm{~L} / \mathrm{min}^{15}$ and $7.75 \mathrm{~mL} / \mathrm{kg} / \mathrm{min} .{ }^{16}$ As a consequence, the total exercise time during a maximum test differed depending on whether the subject used the handrail for support $\left(9.9 \pm 4.1 \mathrm{~min}\right.$ vs $8.0 \pm 2.9 \mathrm{~min}$, respectively). ${ }^{19}$ 
Table 3. Comparison of Tests at the Peak of Training

\begin{tabular}{|c|c|c|c|c|}
\hline Subject Attributes & ISWT-T & ISTW-H & $P$ & Effect Size \\
\hline Speed, $\mathrm{km} / \mathrm{h}$ & $5.0(0.6)$ & $4.3(0.6)$ & $<.001$ & 1.17 \\
\hline$\dot{\mathrm{V}}_{\mathrm{O}_{2}}, \mathrm{~L} / \mathrm{min}$ & $0.95(0.4)$ & $0.85(0.3)$ & .007 & 0.28 \\
\hline$\dot{\mathrm{V}}_{\mathrm{O}_{2}}, \mathrm{~mL} / \mathrm{kg} / \mathrm{min}$ & $15.3(5.0)$ & $14.1(4.0)$ & .055 & 0.27 \\
\hline$\dot{\mathrm{V}}_{\mathrm{O}_{2}}, \%$ of predicted & $57.6(28.6)$ & $53.2(25.0)$ & .046 & 0.18 \\
\hline$\dot{\mathrm{V}}_{\mathrm{CO}_{2}}, \mathrm{~L}$ & $0.8(0.4)$ & $0.7(0.3)$ & .005 & 0.29 \\
\hline$\dot{\mathrm{V}}_{\mathrm{E}}, \mathrm{L} / \mathrm{min}$ & $20.2(7.0)$ & $19.0(6.0)$ & .06 & 0.18 \\
\hline$\dot{\mathrm{V}}_{\mathrm{E}} / \mathrm{MVV}$ & $0.3(0.1)$ & $0.3(0.1)$ & .09 & 0.00 \\
\hline Respiratory quotient & $0.9(0.1)$ & $0.8(0.1)$ & .17 & 1.00 \\
\hline Heart rate, beats/min & $113(11)$ & $109(16)$ & .03 & 0.29 \\
\hline Heart rate, $\%$ of predicted & $66.4(11.0)$ & $63.8(10.3)$ & .03 & 0.19 \\
\hline $\mathrm{S}_{\mathrm{pO}_{2}}, \%$ & $92(4)$ & $92(4)$ & .28 & 0.00 \\
\hline Borg dyspnea & $2.5(1-4)$ & $2(1-4)$ & .47 & 0.04 \\
\hline Borg lower limb fatigue & $2(1-4)$ & $2(1-4)$ & .89 & 0.02 \\
\hline $\mathrm{SBP}, \mathrm{mm} \mathrm{Hg}$ & $135(18)$ & $133(2)$ & .57 & 0.17 \\
\hline $\mathrm{DBP}, \mathrm{mm} \mathrm{Hg}$ & $83(12)$ & $80(7)$ & .22 & 0.31 \\
\hline \multicolumn{5}{|c|}{$\begin{array}{l}N=24 \\
\text { Values are expressed as mean (SD), except Borg scales, which are expressed as median (interquartile range). } \\
\text { ISWT = incremental shuttle walk test (-T, on a treadmill; }-\mathrm{H} \text {, in a hallway) } \\
\dot{\mathrm{V}}_{\mathrm{O}_{2}}=\text { oxygen uptake } \\
\mathrm{V}_{\mathrm{CO}_{2}}=\text { carbon dioxide production } \\
\mathrm{V}_{\mathrm{E}} / \mathrm{MVV}=\text { minute ventilation/maximum voluntary ventilation } \\
\mathrm{SBP}=\text { systolic blood pressure } \\
\mathrm{DBP}=\text { diastolic blood pressure }\end{array}$} \\
\hline
\end{tabular}

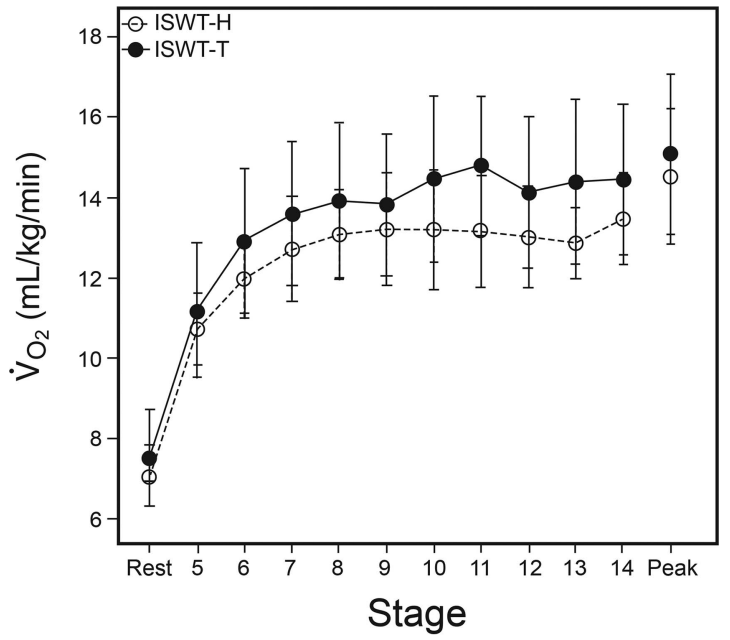

Fig. 2. Oxygen consumption $\left(\dot{\mathrm{V}}_{\mathrm{O}_{2}}\right)$ during training session with the speed obtained from ISWT-H and ISWT-T. Values are expressed as mean and $95 \% \mathrm{CI}$. $N=24$. ISWT = incremental shuttle walk test, $\mathrm{H}=$ hallway, and $\mathrm{T}=$ treadmill.

Unlike the cited studies, no differences in the physiological responses were found between the 2 methods of performing the ISWT in this study. It is possible that the use of handrail support during the ISWT-T equalized these responses by diminishing the demand during the test, despite the longer distance traveled.

In this study, the intensity of the handrail support also influenced the subjects' responses to exercises. There were significant physiological differences when the hands were free, when hands were only used for support (8.4\% reduction in $\dot{\mathrm{V}}_{\mathrm{O}_{2}}$ and $3.5 \%$ reduction in heart rate), and when hands held the handrail with a strong grip (21\% reduction in $\dot{\mathrm{V}}_{\mathrm{O}_{2}}$ and $14.8 \%$ reduction in heart rate). ${ }^{17}$ The same is true for the perception of effort, ${ }^{17}$ and a similar effect (reduction in $\dot{\mathrm{V}}_{\mathrm{O}_{2}}$ and heart rate) occurred when hand support was permitted during a step exercise. ${ }^{30}$

Seventy-five percent of the maximum speed achieved for both methods of performing the ISWT was established for the training sessions. Therefore, due to the better performance on the ISWT-T, the work load for the training session following this modality was higher in comparison to the work load determined by the ISWT-H (Table 3). Thus, training based on the ISWT-T led to greater metabolic, ventilatory, and cardiac demands. However, the difference in work load between the 2 tests was small ( 0.7 $\mathrm{km} / \mathrm{h}$ ), and the physiological responses to exercise as well as the perception of effort during the tests was not clinically substantial.

The validity of the ISWT for the determination of the training load is recognized in patients with $\mathrm{COPD}^{32}$ and other chronic lung conditions. ${ }^{31}$ The ISWT has also been used to determine training loads for patients with bronchiectasis, ${ }^{2}$ but the acute physiological responses during a training session have not previously been evaluated. Our results reveal that the physiological responses are compatible with a moderate intensity regardless of how the train- 
ing load was determined. This is an important aspect, as the benefits acquired during physical training are related to exercise intensity, with a direct influence on better results regarding the therapeutic response and evolution of the patient's clinical condition. ${ }^{23}$ When patients with COPD participate in high-intensity training, they experience greater physiological benefits and more effective results compared to low-intensity training. ${ }^{29}$ It is therefore possible that better results would also be obtained with a work load greater than $75 \%$ of the maximum speed achieved on the ISWT. ${ }^{33}$

Although the ISWT can be used to determine the training work load for patients with chronic lung disease, ${ }^{2,32}$ it should be pointed out that this test is not adequate for determining the appropriate intensity of training for healthy individuals. While patients generally interrupt these tests due to limitations imposed by their chronic lung condition, ${ }^{1}$ healthy individuals tend to interrupt the ISWT when they become unable to match the increasing pace without running, which is not permitted during the test. Therefore, it is not a good measure of their physical limitations.

\section{Implications of the Study}

Our results have clinical implications that should be considered. In patients with bronchiectasis, the ISWT-T with handrail support should not be considered an alternative to the ISWT-H to overcome limitations to performing the test in its original form, because handrail support reduces the energy expenditure and overestimates the distance traveled. Therefore, the test should be used in its original form. Independent of how the physical training load was determined (on a treadmill or in a hallway), the subjects' responses during training were still compatible with moderate intensity and were below what is recommended for aerobic training. As a result, we recommend that the training load on a treadmill with handrail support be higher than $75 \%$ of the velocity achieved on the ISWT-H.

\section{Limitations of the Study}

This study has limitations that should be addressed. The use of the traditional version of the ISWT may have underestimated the maximum performance of the subjects because running was not permitted. Because bronchiectasis compromises pulmonary function and functional capacity to different degrees, some subjects may still be able to run and could therefore have higher training loads and physiological responses. However, the aim of this study was to compare the original version of the ISWT conducted in a hallway with that performed on a treadmill. It is possible that the order of the tests could influence the results, but the tests were performed a day apart, so there was sufficient time for rest. The small sample size can restrict external validity of the findings of this study. Because the physiological responses to training were evaluated on a treadmill that offered handrail support, further studies are therefore needed to determine how subjects with bronchiectasis would respond to training without this type of support.

\section{Conclusion}

Subjects with bronchiectasis performed better on the ISWT on a treadmill with handrail support than they did on the same test in a hallway. Although the physiological responses and perception of effort were similar, the 2 forms of the test are not interchangeable. The training intensity was higher when determined using the ISWT-T, but the physiological responses during treadmill training with handrail support were clinically similar and corresponded to a moderate intensity, although still below the recommendation for aerobic training.

\section{REFERENCES}

1. Singh SJ, Morgan MD, Scott S, Walters D, Hardman AE. Development of a shuttle walking test of disability in patients with chronic airways obstruction. Thorax 1992;47(12):1019-1024.

2. Lee AL, Hill CJ, Cecins N, Jenkins S, McDonald CF, Burge AT, et al. The short and long term effects of exercise training in noncystic fibrosis bronchiectasis: a randomised controlled trial. Respir Res 2014;15(1):44.

3. Holland AE, Spruit MA, Singh SJ. How to carry out a field walking test in chronic respiratory disease. Breathe (Sheff) 2015;11(2):128-139.

4. Stevens D, Elpern E, Sharma K, Szidon P, Ankin M, Kesten S. Comparison of hallway and treadmill six-minute walk tests. Am J Respir Crit Care Med 1999;160(5 Pt 1):1540-1543.

5. De Almeida FG, Victor EG, Rizzo JA. Hallway versus treadmill 6-minute-walk tests in patients with chronic obstructive pulmonary disease. Respir Care 2009;54(12):1712-1716.

6. Swerts PM, Mostert R, Wouters EF. Comparison of corridor and treadmill walking in patients with severe chronic obstructive pulmonary disease. Phys Ther 1990;70(7):439-442.

7. Beaumont A, Cockcroft A, Guz A. A self paced treadmill walking test for breathless patients. Thorax 1985;40(6):459-464.

8. Moloney ED, Clayton N, Mukherjee DK, Gallagher CG, Egan JJ. The shuttle walk exercise test in idiopathic pulmonary fibrosis. Resp Med 2003;97(6):682-687.

9. Almodhy M, Beneke R, Cardoso F, Taylor MJ, Sandercock GR. Pilot investigation of the oxygen demands and metabolic cost of incremental shuttle walking and treadmill walking in patients with cardiovascular disease. BMJ 2014;4(9):e005216.

10. Lee SJ, Hidler J. Biomechanics of overground vs. treadmill walking in healthy individuals. J Appl Physiol 2008;104(3):747-755.

11. Chang MD, Shaikh S, Chau T. Effect of treadmill walking on the stride interval dynamics of human gait. Gait Posture 2009;30(4): 431-435.

12. Ortega JD, Fehlman LA, Farley CT. Effects of aging and arm swing on the metabolic cost of stability in human walking. J Biomech 2008;41(16):3303-3308.

13. Umberger BR. Effects of suppressing arm swing on kinematics, kinetics, and energetics of human walking. J Biomech 2008;41(11): 2575-2580. 


\section{Incremental Shuttle Walk Test to Prescribe Exercise}

14. Holland AE, Spruit MA, Troosters T, Puhan MA, Pepin V, Saey D, et al. An official European Respiratory Society/American Thoracic Society technical standard: field walking tests in chronic respiratory disease. Eur Respir J 2014;44(6):1428-1446.

15. Foster C, Crowe AJ, Daines E, Dumit M, Green MA, Lettau S, et al. Predicting functional capacity during treadmill testing independent of exercise protocol. Med Sci Sports Exerc 1996;28(6):752-756.

16. Hoffmann CL, Dougherty C, Abkarian HK, Fox M, Juris PM. The reduction of metabolic cost while using handrail support during inclined treadmill walking is dependent on the handrail use instruction. Int J Exercise Science 2014;7(4):339-345.

17. Berling J, Foster C, Gibson M, Doberstein S, Porcari J. The effect of handrail support on oxygen uptake during steady state treadmill exercise. J Cardiopulm Rehabil 2006;26(6):391-394.

18. Arellano CJ, Kram R. The energetic cost of maintaining lateral balance during human running. J Appl Physiol 2012;112(3):427434.

19. McConnell T, Foster C, Conlin N, Thompson N. Prediction of functional capacity during treadmill testing: effect of handrail support. J Cardiopulm Rehabil 1991;11(4):255-260.

20. Spruit MA, Singh SJ, Garvey C, ZuWallack R, Nici L, Rochester C, et al. An official American Thoracic Society/European Respiratory Society statement: key concepts and advances in pulmonary rehabilitation. Am J Respir Crit Care Med 2013;188(8):e13-e64.

21. Pasteur M, Bilton D, Hill A, Stockley RA, Wilson R, Pasteur MC, et al. British Thoracic Society guidelines for non-CF bronchiectasis. Thorax 2010;65(Suppl 1):i1-i58.

22. WHO Expert Committee. Physical status: the use and interpretation of anthropometry. World Health Organ Tech Rep Ser 1995;854:1-452.

23. Sociedade Brasileira de Pneumologia. Diretrizes para testes da função pulmonar. J Pneumol 2002;28(Suppl 3):S44-S58

24. Pereira CAC, Sato T, Rodrigues SC. New reference values for forced spirometry in white adults in Brazil. J Bras Pneumol 2007;33(4):397-406.
25. Kovelis D, Segretti NO, Probst VS, Lareau SC, Brunetto AF, Pitta F. Validação do Modified Pulmonary Functional Status and Dyspnea Questionnaire e da escala do Medical Research Council para o uso em pacientes com doença pulmonar obstrutiva crônica no Brasil. J Bras Pneumol 2008;34(12):1008-1018.

26. Borg GA. Psychophysical bases of perceived exertion. Med Sci Sports Exerc 1982;14(5):377-381.

27. Probst VS, Hernandes NA, Teixeira DC, Felcar JM, Mesquita RB, Gonçalves CG, et al. Reference values for the incremental shuttle walking test. Respir Med 2012;106(2):243-248.

28. Garber CE, Blissmer B, Deschenes MR, Franklin BA, Lamonte MJ, Lee IM, et al. American College of Sports Medicine position stand. Quantity and quality of exercise for developing and maintaining cardiorespiratory, musculoskeletal, and neuromotor fitness in apparently healthy adults: guidance for prescribing exercise. Med Sci Sports Exerc 2011;43(7):1334-1359.

29. Casaburi R, Patessio A, Ioli F, Zanaboni S, Donner CF, Wasserman $\mathrm{K}$. Reductions in exercise lactic acidosis and ventilation as a result of exercise training in patients with obstructive lung disease. Am Rev Respir Dis 1991;143(1):9-18.

30. Christman SK, Fish AF, Bernhard L, Frid DJ, Smith BA, Mitchell L. Continuous handrail support, oxygen uptake, and heart rate in women during submaximal step treadmill exercise. Res Nurs Health 2000; 23(1):35-42.

31. Parreira VF, Janaudis-Ferreira T, Evans RA, Mathur S, Goldstein RS, Brooks D. Measurement properties of the incremental shuttle walk test: a systematic review. Chest 2014;145(6):1357-1369.

32. Revill SM, Morgan MD, Singh SJ, Williams J, Hardman AE. The endurance shuttle walk: a new field test for the assessment of endurance capacity in chronic obstructive pulmonary disease. Thorax 1999;54(3):213-222.

33. Hill K, Dolmage TE, Woon L, Coutts D, Goldstein R, Brooks D. A simple method to derive speed for the endurance shuttle walk test. Respir Med 2012;106(12):1665-1670. 